\title{
Uma análise exploratória de práticas associadas à Ética Computacional através do ciberespaço brasileiro
}

\author{
Luiz Paulo Carvalho ${ }^{1}$, Jonice Oliveira ${ }^{1}$, Flávia Maria Santoro ${ }^{2}$ \\ ${ }^{1}$ Programa de Pós-Graduação em Informática (PPGI) - UFRJ \\ Rio de Janeiro, RJ - Brasil \\ ${ }^{2}$ Departamento de Ciência da Computação (DCC) - UERJ \\ Rio de Janeiro, RJ - Brasil \\ luiz.paulo.carvalho@ppgi.ufrj.br, joniceddcc.ufrj.br, \\ flavia@ime.uerj.br
}

\begin{abstract}
Ethical Decision-Making (EDM) is a multifaceted phenomenon. However, scholars often neglect its heterogeneous nature. Despite the diversity of approaches (for example, influencing factors, EDM models, measurement scales adopted), empirical research has failed to generate cumulative results. This paper analyzed two hundred and thirty-one responses to a questionnaire submitted to computer experts about "immoral or unethical practices" that they have been involved in, directly or indirectly. We intend to investigate these phenomena through a disruptive and innovative approach in Ethics, called Ethics of Resistance, by a mixed approach; without criminal, legal or penal judgment, considering the maximum number of elements and possible factors extracted.
\end{abstract}

Resumo. A Tomada de Decisão Ética (TDE) é um fenômeno multifacetado. No entanto, os estudiosos frequentemente negligenciam sua natureza heterogênea. Apesar da diversidade de abordagens (por exemplo, fatores de influência, modelos de TDE, escalas de medição adotadas), a pesquisa empírica também falhou em gerar resultados cumulativos. Neste artigo, analisamos duzentas e trinta e uma respostas a um questionário veiculado majoritariamente entre especialistas em Computação, associadas a "práticas imorais ou antiéticas" que eles tenham se envolvido, direta ou indiretamente. Nossa intenção é investigar estes fenômenos por uma ótica disruptiva e inovadora, a Ética da Resistência; por abordagem mista; sem juízo criminal, legal ou penal; considerando o máximo de elementos e fatores possíveis extraídos.

\section{Introdução}

A Tabela 1 expõe um panorama ético hipotético, contendo uma lista de cenários, com contexto e prática. Antes de prosseguir, se possível, reflita sobre este conteúdo.

Há cinquenta anos atrás [Bohr e Kaplan 1971] cunhavam um termo seminal para o tópico de Tomada de Decisão Ética (Ethical Decision-Making - EDM), “complex ethical-decision making issue" (questão de tomada de decisão ética complexa) 
[Luca Casali e Perano 2020]. No contexto dos protestos de profissionais da área de assistência médica, um trecho consegue captar cirurgicamente este termo:

À medida que profissionais mais jovens percebem os aspectos sociais de seu papel, passam a ver a prestação de cuidados de saúde como inserida em uma matriz social. Talvez por causa do impacto dos movimentos pelos direitos civis e pela paz, os jovens profissionais têm questionado se a prestação de "serviço de ambulância" às vítimas da sociedade é preferível a mudar as situações subjacentes que produzem acidentes. A disseminação do protesto atesta o fato de que muitos funcionários da área de saúde não podem mais divorciar o tratamento individual de seu contexto social. [Bohr e Kaplan 1971]

Tabela 1. Um recorte da vida e história de João no ciberespaço

\begin{tabular}{|c|c|c|}
\hline$\#$ & Contexto & Prática \\
\hline 1 & $\begin{array}{l}\text { Março de 2021. João tem dezenove anos de idade; matri- } \\
\text { culado e ativo em um curso superior de graduação da área de } \\
\text { Computação; possui conhecimentos especializados no tópico. }\end{array}$ & João "pirateia" filmes. \\
\hline 2 & $\begin{array}{l}\text { Idem ao item } 1 \text {. O pai de João é assinante da plataforma de } \\
\text { streaming Disney+, por R } \$ 27,90 \text { mensais. João está interes- } \\
\text { sado no filme "Raya e o Último Dragão" na Disney+, para } \\
\text { isso precisa pagar um adicional de R } \$ 69,90 \text { para assistir con- } \\
\text { juntamente à estreia nos cinemas e na plataforma, disponível } \\
\text { apenas no pacote Premier Access [Lima 2021]. }\end{array}$ & $\begin{array}{l}\text { João "pirateia" um filme para assis- } \\
\text { tir, já consumindo serviço similar } \\
\text { da mesma empresa. }\end{array}$ \\
\hline 3 & $\begin{array}{l}\text { Idem aos itens } 1 \text { e } 2 \text {. O pai de João está desempregado por } \\
\text { influência indireta da pandemia, está trabalhando informal- } \\
\text { mente através de aplicativos de entrega de comida para sus- } \\
\text { tentar sua família, em situação econômica precária. João tem } \\
\text { duas irmãs pequenas, Disney+ as distrai e serve como entre- } \\
\text { tenimento. Elas querem muito assistir ao filme, por causa do } \\
\text { distanciamento social elas mantém contato com colegas pela } \\
\text { Internet, e todos no grupo delas disseram que vão ver perto } \\
\text { da estreia (sem garantia de que isso seja verdade). João e } \\
\text { suas irmãs respeitam o isolamento social e não saem de casa. } \\
\text { João ama suas irmãs, é tecnopoliticamente consciente e se } \\
\text { questiona porque a Disney+ precisa cobrar um valor adicional } \\
\text { absurdo para acesso antecipado por um conteúdo que estará } \\
\text { disponível em breve, bem mais caro do que um ingresso de } \\
\text { cinema. }\end{array}$ & $\begin{array}{l}\text { João "pirateia" um filme que deseja } \\
\text { assistir, já consumindo o serviço si- } \\
\text { milar da mesma empresa, para dei- } \\
\text { xar suas irmãs felizes e despreocu- } \\
\text { par e poupar seu pai. }\end{array}$ \\
\hline 4 & $\begin{array}{l}\text { Idem aos itens } 1,2 \text { e } 3 \text {. João está sofrendo os revezes men- } \\
\text { tais, sociais e físicos do cenário pandêmico. Seu pai está } \\
\text { constantemente estressado pelas condições precárias de tra- } \\
\text { balho [Oliveira 2020], pressiona João que largue a faculdade } \\
\text { ou "faça algum dinheiro" com ela. O custo para assistir } \\
\text { "Raya e o Último Dragão" é } \approx 5 \% \text { da renda mensal do pai } \\
\text { de João. João se questiona eticamente se "piratear" o filme } \\
\text { realmente vai prejudicar as pessoas envolvidas na sua pro- } \\
\text { dução, na Internet predomina o discurso de defesa às ope- } \\
\text { rações ou lucro da empresa [Eriksen } 2021 \text { ] ou falas incoe- } \\
\text { rentes como "protege o resto da cadeia de distribuição (alu- } \\
\text { guel/físico/cabo/streaming) abaixo" [Schaefer } 2020 \text { ], sendo } \\
\text { impreciso como essa cobrança adicional protege ou favorece } \\
\text { alguém que não a própria empresa. A própria assinatura da } \\
\text { Disney+, R } \$ 27,90 \text {, impacta significativamente nas contas do } \\
\text { mês. }\end{array}$ & $\begin{array}{l}\text { João "pirateia" um filme que deseja } \\
\text { assistir, já consumindo o serviço si- } \\
\text { milar da mesma empresa, para dei- } \\
\text { xar suas irmãs felizes e despreocu- } \\
\text { par e poupar seu pai. Conscien- } \\
\text { temente e racionalmente considera } \\
\text { imoral a taxa-extra para acesso an- } \\
\text { tecipado. João mantém seu cliente } \\
\text { torrent constantemente operando e } \\
\text { compartilhando o arquivo do filme } \\
\text { e dissemina o link em grupos de } \\
\text { pessoas igualmente contrárias à so- } \\
\text { bretaxa da plataforma. }\end{array}$ \\
\hline
\end{tabular}


Neste recorte de [Bohr e Kaplan 1971] percebemos elementos próprios ou externos ao domínio e contexto primário da pesquisa. A idade dos profissionais, movimentos pelos direitos civis e pela paz, as ditas vítimas da sociedade, os acidentes, as ambulâncias, dentre outros. Com a expansão do contexto pertinente à análise, acrescentam-se dimensões e complexidade, dificultando posterior eficácia e eficiência de uma modelagem positivista, determinística e objetiva [Bar-Yam 2002]. A pluralidade ecossistêmica torna necessária uma abordagem interdisciplinar ou transdisciplinar [Sovacool 2014].

Uma análise de EDM, a qual aprofundamos na Seção 2, progride em complexidade conforme são adicionadas informações ao contexto. Caso consideremos a Ética como a disciplina que estuda o "certo" e o "errado", a tendência de definir as práticas de João como "erradas" é proporcional à numeração do cenário na Tabela 1, a perspectiva empírica representando a sociomaterialidade e a concretude. O reducionismo dos estudos de EDM é resumido por [Luca Casali e Perano 2020]:

Por uma perspectiva empírica, EDM é um fenômeno multifacetado. No entanto, os estudiosos frequentemente negligenciam sua natureza heterogênea. Apesar da diversidade de abordagens (por exemplo, fatores de influência, modelos de EDM, escalas de medição adotadas), a pesquisa empírica também falhou em gerar resultados cumulativos. Uma explicação é a falta de consenso sobre a lista de fatores de influência e o grau em que cada fator influencia os tomadores de decisão. [Luca Casali e Perano 2020]

Se retornamos à Tabela 1, observamos a heterogeneidade e pluralidade de atores e influências acerca da vida de João. A simplificação e redução do panorama holístico de suas experiências tanto habilita uma análise precisa quanto limita João aos dados ou informações definidos no respectivo contexto atrelado ao cenário. Poderíamos, de forma similar, transladar nossa lente analítica à plataforma Disney+, às irmãs ou o pai de João, ao aplicativo de entrega de comida e a empresa proprietária do mesmo, aos conhecimentos especializados em Computação de João, à comunidade de "pirataria", dentre outros.

O cenário de João serve como uma ilustração de que a análise da vida e da itinerância de alguém é complexa e multifacetada. Os cenários expõem disputas e conflitos entre nós, como João; sub-redes, as famílias prejudicadas pela pandemia; ou redes inteiras, a plataforma Disney+; de forças, privilégios e poderes desiguais entre partes. $\mathrm{O}$ cenário \#1 pode nos conduzir à impressão de que João é meramente um pós-adolescente, agindo irracionalmente e sem consciência crítica, inclinado a apropriação indevida de bens digitais, infração de propriedade intelectual e uso de conhecimento especializado para fins maliciosos; o cenário \#5, complementado em dados, expõe que João age racionalmente e conscientemente em propósito, intenção e objetivo, e as definições cartesianas embaralham-se, confundindo-se. A "pirataria" de João é um ato de resistência contra a tentativa da Disney+ de sobretaxar usuários reforçando a cultura de consumismo imediatista [Sklair 2012], mesmo apoiando a assinatura do serviço de streaming da plataforma.

Desenvolvemos e veiculamos um questionário, mediante formulário online ${ }^{1}$. Analisamos duzentas e trinta e uma respostas majoritariamente de especialistas em Computação associadas a "práticas imorais ou antiéticas" que eles tenham se envolvido, direta ou indiretamente. Nossa intenção é investigar estes fenômenos por uma ótica disruptiva e inovadora na Ética, chamada Ética da Resistência [Klikauer 2014, Christians 2007, Alakavuklar e Alamgir 2018]; por abordagem qualitativa ou mista; sem juízo criminal,

\footnotetext{
${ }^{1}$ https://forms.gle/qZX5SFaeHQ3KT7s96. Disponível em 20/03/2021.
} 
legal ou penal; considerando o máximo de elementos e fatores possíveis extraídos. Especialistas em Computação, institucionalmente instruídos, possuem consciência crítica de suas práticas classificadas como "antiéticas" ou "imorais"? Quais análises podem ser extraídas destas práticas? As ações são arrazoadas? Podemos atravessar princípios éticos através das respostas?

A Seção 2 apresenta fundamentos sobre Ética, Tomada de Decisão Ética e Ética da Resistência; na Seção 3 apresentamos a metodologia e método de pesquisa aplicados, encadeado a análise e contribuições principais; a Seção 4 conclui com breve discussão de possíveis soluções e propostas de pesquisas futuras.

\section{2. Ética e afins}

Ética fundamentalmente estuda a prática de justificar o questionamento "o que devo fazer?", a partir do ponto de vista da razão, sem irmos contra nós mesmos ou que nos anulemos, coincidindo o subjetivo com o objetivo, isenta de particularização e relativização. É um acordo entre o interesse individual e os demais sujeitos de racionalidade, unidade entre interesse pessoal e interesse moral. Transcendendo a contemplação, ao agir somos dotados de racionalidade prática e razões para agir, justificativas. O ethos está indissociavelmente associado à "prática", a uma comunidade, inserida em uma comunidade ou sociedade [Ferraz 2014]. O sujeito da Ética, por sua vez, é a Moralidade [Fieser 2020].

Estes aspectos basilares da Ética apontam uma associação da Ética Aplicada aos especialistas de respectivos domínios de aplicação. Discorremos sobre pessoas instruídas formalmente em Computação, correspondendo à esfera especializada deste domínio específico [Habermas 1997]; esperando-se que os mesmos tenham consciência deontológica, virtuosa ou consequencialista de suas ações, isto é, intelectualidade ética. Por exemplo, João está consciente de suas ações no domínio da Computação, a priori, a posteriori, e relacionada às suas virtudes, tanto concreta quanto simbolicamente. É consciente do impacto e influência no âmbito idealístico e exemplar, por exemplo, "João pratica isso e é especialista neste domínio, logo, esta é uma prática válida”.

Consciência ética, generalista ou associada a um domínio específico, é facultada à racionalidade, sendo assim, a todos os seres humanos. Entretanto, a esfera pública e a esfera especializada [Habermas 1997] se diferenciam considerados objetos especializados, por exemplo, se recorre ao especialista na prática médica ao constatar-se necessidade de uma cirurgia médica, ao invés de pessoa qualquer em âmbito amplo. Espera-se que o médico cirurgião seja dotado de consciência ética ao praticar sua especialidade, tanto técnica quanto contemplativa, instruída durante sua itinerância formativa institucionalizada, por exemplo, formação universitária. A mesma analogia pode ser intercambiada à Computação e seus respectivos especialistas. Compreende-se o especialista em Computação, assim como o especialista em Medicina Cirúrgica, como dotado de razão e proficiência técnica e ética. Como João utiliza seus conhecimentos especializados para "piratear" sendo especialista neste domínio, espera-se racionalidade nesta ação.

Sendo a Ética essencialmente prática, EDM analisa como pessoas, grupos ou organizações tomam decisões a partir de uma perspectiva ética. Ao limite de nosso conhecimento, é ausente ao contexto brasileiro um estudo exploratório sobre EDM relacionada ao domínio da Computação. Como trabalhos próximos deste tema, [Sposito 2011] trata de uma pesquisa envolvendo alunos de cursos superiores em Computação e a relação dos 
mesmos com Ética; [Barcaro e Freire 2009] apontam a importância do currículo de Computação conter explicitamente o ensino de Ética; e [Masiero 2013] com uma abordagem ampla de Ética em Computação no Brasil. Ampliando ao contexto de análise externo ao brasileiro, [Luca Casali e Perano 2020] apresentam uma abrangente revisão sistemática da literatura sobre o tema, somatizando outras revisões similares.

Predominantemente, EDM divide-se em normativa e descritiva. A abordagem normativa estrutura e formaliza tomada de decisão a ser realizada; descritiva analisa e avalia elementos que compõe determinada tomada de decisão realizada [Torres 1998]. O que diferencia EDM de tomadas de decisão genéricas é o aspecto intrínseco principiológico associado a constructos oriundos da Ética, por exemplo, as linhas de pensamento ético. Ademais, podemos especializar EDM ao domínio da Computação, pura ou aplicada. Diferenciar e isolar Computação, entre pura (ou técnica) e aplicada, é desafio externo a este trabalho. Exemplificando de forma simples, pura trata da pesquisa ou desenvolvimento de um algoritmo para dificultar o rastreamento de conteúdos protegidos por propriedade intelectual "pirateados"; aplicada trata dos impactos e influências deste algoritmo.

Aqui lidamos com EDM em Computação Aplicada, que nomearemos ISEDM (Information Systems Ethical Decision-Making). Os elementos epistemológicos fundamentais que compõe Sistemas de Informação (SI) permitem um diálogo conceitual parcimonioso entre as partes, considerando Software, Harware, Armazenamento de Dados e Redes, que se isolados configuram Computação pura; somados com pessoas e procedimentos [Stair e Reynolds 2018], e integrados compõe SI. Transborda-se o limite técnico primando por uma pluralidade interdisciplinar, uma análise complexa, dada que a imanência das percepções da realidade localiza-se fora da Computação em si. Alinhado à [Gregor 2006], encontramo-nos no atravessamento entre disciplinas tecnológicas e extrínsecas a ela, propondo análises ricas, plurais e transfronteiriças.

Como exemplos de dilemas em ISEDM, uso de plataformas digitais por líderes governamentais para disseminar desinformação [Lisboa et al. 2020]; romantização de dataveillance e cyberstalking deteriorando a Privacidade [Carvalho et al. 2020]; racismo algorítmico [Silva 2020]; profissão e opressão de gênero em Computação [Ribeiro et al. 2020]; responsabilidade algorítmica e personalidade eletrônica [Silveira 2020]; impactos e influências de Language Models (LM) [Bender et al. 2021].

Cada cenário de ISEDM, conduzido por determinado(s) princípio(s) ético(s), resultará em uma avaliação moral distinta. Ressaltando o aspecto semântico, corretude e completude, do cenário em questão e do objeto analisado, neste caso, a prática de João. Algumas possíveis decisões morais baseadas em vertentes principiológicas éticas [Fieser 2020, Ferraz 2014] podem ser: (i) Hedonismo ou Egoísmo, assistir o filme, pagando ou não, garante a João o máximo de prazer individual; (ii) Kantiano ou Imperativos Categóricos, João deve fazer aos outros o que gostaria que fizessem consigo, se João não quer que se apropriem de sua produção intelectual sem arcar com o tempo e o recurso investido, não deve fazer o mesmo à Disney+, e idealisticamente João incentiva essa prática, piorando seu quadro; (iii) Ética do Afeto (Ethics of Care), João coloca a felicidade e diversão de suas irmãs, emocionalmente prejudicadas pela pandemia, acima de razões restritivas ou categoricamente imperativas que o impeçam; (iv) Consequencialismo, pensando em custo-benefício, João não irá abrir mão de comer ou de que suas irmãs comam para assistir um filme, assim como a probabilidade de ser preso ou pe- 
nalizado criminalmente é ínfima e a alegria de suas irmãs é garantida; (v) Baseado em Deveres ou Contratualismo, João não tem certeza se baixar apenas uma cópia do filme, sem compartilhá-lo, por vias alternativas para fins não comerciais ou lucrativos é crime ou se fere seu contrato social implícito com o Estado, a legislação é ambígua e opaca neste âmbito e João não dispõe de tempo para realizar uma análise jurídica minuciosa; (vi) Utilitarismo, uma análise nesta vertente ou é improvável ou potencialmente enviesada, pela impossibilidade de objetiva e claramente analisar os dados, por exemplo, "piratear o filme" realmente causaria prejuízo à produção do filme? Toda produção ou apenas as partes interessadas financeiramente? Como isso acarretaria em dolo à equipe no geral?

Neste trabalho dialogamos com a Ética da Resistência [Klikauer 2014, Christians 2007, Alakavuklar e Alamgir 2018]. Seus fundamentos se baseiam em privilégio, poder, inclusão, posicionamento político e sustentabilidade. Diferente da ótica quantitativa utilitarista ou da visão reducionista idealista Kantiana, a crítica ética é complexa e combativa. Neste sentido, o próprio cenário de João é o menos indicado, porque o mesmo está em uma posição desfavorecida. Para uma crítica contundente e rica, transladar a análise à Disney+ ou à empresa de gestão do aplicativo de entrega de comida traria uma visão efetivamente válida. Analisar a ISEDM de João é analisar um nó ínfimo se comparado com o potencial de análise da ISEDM destes outros atores, por exemplo, cobrar um preço absurdo adicional para acessar baseado em apenas um produto? Melhorar as condições de pagamento e trabalho dos entregadores dos aplicativos? Nada disso é analisado, então a primeira vista a complementação de cenário parece uma tentativa de "justificar" as práticas de João, só que pensamos eticamente nas práticas dos demais atores envolvidos? Ou todo ônus recai sobre João?

Em primeiro momento (Tabela 1, \#1) arrazoa-se que João é um criminoso cibernético, pela sua prática. Conforme incrementa-se complexidade, percebe-se que João tanto não se guia por Egoísmo, caso contrário João incentivaria seu pai a cancelar a assinatura da Disney+ e "piratearia" todo o conteúdo. Ele também está interessado em boicotar a lógica consumista reforçada pela plataforma para sua comunidade digital, mantendo o torrent ativo e compartilhando-o em grupos semelhantes. Em momento algum João advogou pela abolição da assinatura da Disney+, ou pela "pirataria" de todo seu conteúdo, ele cirurgicamente buscou conhecimento sobre o tema e tomou uma decisão ética. Além de gozar da obra, João entende que pessoas significativas a ele também devem fazê-lo. E esta é a forma de João operar seus ideais de combate e aversão à cultura do consumismo imediatista e à prática da Disney+. Pois, como ele mesmo leu, essa pode se tornar uma tendência neste nicho [Schaefer 2020, Eriksen 2021].

\section{Análise ética das práticas no ciberespaço brasileiro}

A partir da metodologia de Questionário [Recker 2013], coletamos e analisamos dados de duzentos e trinta e um respondentes especialistas, ou em processo de especialização, em Computação. Apesar do foco ser nesta população específica e para evitar comportamento excludente, abarcamos respondentes externos à Computação (12 no total, $\approx 5 \%)$. Em respeito à reprodução, verificação e validação, disponibilizamos a base de dados online ${ }^{2}$.

Respeitando o anonimato dos respondentes, nesta pesquisa analisamos os dados coletados em quatro perguntas, detalhada nas Seções A. Considerando o intervalo de dois

\footnotetext{
${ }^{2}$ https://cutt.ly/SxTJVQb. Disponível em 20/03/2021.
} 
meses atrás até o dia de hoje, você cometeu alguma prática que poderia ser considerada imoral ou anti-ética em Computação? Qual(is)? Se não cometeu nenhuma, só responder "Nenhuma"; B. [OPCIONAL] O que te motivou ou levou a cometer as práticas da questão anterior (questão A)?; C. O que você sente quando pensa nessas práticas da questão A?; D. [OPCIONAL] Quer complementar livremente a sua resposta anterior (questão C)?; Complemento (opcional). Gostaria de acrescentar qualquer informação?

Nos abstemos de associar as respostas aos dados pessoais dos respondentes, sendo informações alheias ao objetivo primário desta pesquisa. Por exemplo, não nos interessa se "X\% de graduandos realizam mais práticas antiéticas se comparados com pósgraduandos". Sendo esta uma pesquisa ética, em Ética da Resistência, este tipo de construção de conhecimento punitivo e categoricamente inquisitivo configura-se imprestável. Rotular um respondente cursando Direito ou de uma instituição militar como "diferenciado eticamente" reforça um ideal de "escala moral identitária" e configura uma correlação conceitual espúria, elitista e determinística.

Respeitando a proposta de abordagem qualitativa ou mista, o método de pesquisa implementado foi: (i) elaboração do formulário, implementando linguagem informal e simples em vista de engajamento; (ii) sendo uma pesquisa contínua em andamento, extraímos um recorte dos dados em 01/03/2021; (iii) normalização e tratamento da base de dados, por exemplo, respostas inconsistentes à natureza da pergunta; (iv) codificação e categorização das respostas, ainda disponibilizando-as como originalmente dispostas para preservar fidelidade; (v) discussão, elaboração de achados e contribuições. Após normalização e tratamento, cada uma das questões opcionais apresentou a seguinte quantidade de respostas: B. 123; D. 88; C. 190; Complemento. 67.

Categorias de conceituações de respostas foram derivadas indutivamente dos dados usando a abordagem da teoria fundamentada conhecida como "código aberto" [Strauss 1987]. Isto é, considerando as respostas e suas características, cada análise envolveu suas categorias próprias, que são apresentadas associadas às respectivas questões.

Sobre a Questão A, 125 respondentes $(\approx 54 \%$ ) admitiram realizar, ou serem coniventes à realização, de tais práticas. Os testemunhos indicam entre um e sete tipos de práticas: uma, 71 respondentes $(\approx 57 \%)$; duas, 28 respondentes $(\approx 22 \%)$; três, 11 respondentes $(\approx 9 \%)$; quatro, 3 respondentes $(\approx 2 \%)$; cinco, 2 respondentes $(\approx 1 \%)$; sete, 1 respondente $(\approx 1 \%) .9$ respondentes não especificaram quais, restando 116 para análise.

Dos 116 respondentes, $107(\approx 92 \%)$ responderam práticas associadas à Propriedade Intelectual $(\mathrm{PI})$, e $34(\approx 29 \%)$ associadas a outros tipos de prática. Dividimos as demais em Acesso, Regras Acadêmicas, Cyberbullying e Privacidade. Uma resposta foi categorizada como "desconhecido" por falta de dados ("Vendi serviço malicioso"). Estas categorias foram extraídas de [Masiero 2013] e [Barger 2008]. Acesso envolve acessar dados ou serviços não permitidos ao respondente, por exemplo, “[...] invado algumas redes", 9 ocorrências; Regras Acadêmicas envolve infringir ou burlar, explicitamente, normas institucionais acadêmicas, por exemplo, "Paguei para fazerem minha prova durante o EAD”, 21 ocorrências; Cyberbullying é intuitivo, ofensa e opressão contínuas no âmbito digital, 1 ocorrência; Privacidade também é intuitivo, por exemplo, "stalkeei a rede social de algumas pessoas", 2 ocorrências.

Sendo PI a resposta recorrente e significativamente relevante, detalhamos esta ca- 
tegoria. Respondentes apontaram diversos tipos de arquivos envolvidos em suas práticas, 188 no total. Diversas respostas contiveram mais de um tipo, sendo os com mais de $1 \%$ de ocorrência de respostas: Software e Genérico, 5\%; Artigo Acadêmico, 6\%; Série, 8\%; PDF, 12\%; Jogo, 14\%; Filme, $21 \%$ e; Livro, $23 \%$.

Sobre a Questão B, 81 respondentes associaram suas prática à motivações financeiras, desde "não ter o dinheiro" até "não queria pagar"; 17 respondentes foram motivados por qualidade de acesso, como comodidade ou urgência; 12 respondentes justificaram por dificuldade de achar, por exemplo, sem distribuição oficial no Brasil, não acha onde comprar, demora do produto chegar ao Brasil; 8 respondentes indicaram receio de prejuízo por dúvida de legítima utilidade, por exemplo, comprar um jogo e depois se arrepender ou um livro sem certeza de conteúdo ou qualidade; 15 respondentes demonstraram razões ideológicas, isto é, houve racionalidade deontológica, por exemplo, "conhecimento deve ser livre e disponível a todos"; 17 respondentes indicaram pressão acadêmica, por exemplo, "Precisei do conteúdo para a minha pesquisa mas ele é muito caro". Um dos respondentes indicou a motivação como "Requisição da chefia", intensificando o dilema.

Quanto à infração de regras acadêmicas, todas foram associadas com "cola", desde uma questão até pagamento para realização de exames inteiros no EAD. Nesta categoria não houve padronização nas respostas passíveis configuráveis de tipificação, por exemplo, "Questões na prova fora do conteúdo dado e mal formuladas", "Preguiça e o sentimento de estar sobrecarregada", ou "[...] Não queria tirar notas ruins".

A Questão C, com 190 respostas, empregou a Escala Likert variando entre 1, apatia, até 7, culpa, ao pensar sobre a prática da Questão A. Não houve padrão reconhecível ou significativo entre dimensões, por exemplo, a associação entre esta resposta e a quantidade de práticas (Questão A) é inexpressiva. Sendo assim, desmistifica-se o senso comum de consciência e culpabilidade proporcional aos próprios atos ou correlação de auto-crítica pela prática percebida por si mesmo como "antiética" ou "imoral", respondentes indicaram parcela de culpa, demonstrando a complexidade do quadro e sua responsabilidade epistêmica coletiva ou indireta.

Finalizando, Questão D permitia aos respondentes complementação livre, onde percebemos: (i) elogios em relação à informalidade e descontração da comunicação escrita na pesquisa, "Eu gostei de como as questões do formulário foram elaboradas. Quem escreveu tem senso de humor e isso fez com que fosse divertido responder ao formulário"; (ii) recomendações para complementos ou melhorias e abordagens futuras da pesquisa; (iii) refletiram sobre suas próprias práticas enquanto pensavam-respondiam o formulário, gerando reflexão e auto-crítica; (iv) um respondente indicou que a "normalização" destas práticas pode levar outros respondentes a responderem que não as cometeram, pois não as percebem neste valor; (v) um respondente apontou que o formulário apresenta "piadinhas" demais e suspeita que será utilizado seriamente em um trabalho científico; (vi) reforçaram o encaminhamento ideológico e prático para o futuro, por exemplo, "Acredito que se o acesso fosse mais democratizado e unificado as pessoas não recorreriam tanto à pirataria" ou "Vivemos no Brasil, país onde metade mal tem internet e boa parte de estudantes nem um quarto só tem". 


\subsection{Codificação e categorização das motivações e intenções}

Assimilamos as Questões A, B e D criando tópicos e categorias a partir delas, respeitando a subjetividade e autonomia dos respondentes. Consideramos determinantes a motivação intrínseca da prática, a partir dela extraímos reflexões e encaminhamentos. Nesta Seção iremos trazer a crítica geral, a partir das respostas. Analisando cada resposta pontualmente e extraímos conhecimento da síntese qualitativa utilizando preceitos de Ética da Resistência, esta categorização foi naturalística baseada essencialmente nas respostas, sem juízo externo ou determinismo conceitual.

A influência financeira está presente na maioria das respostas, de respondentes que engajaram em práticas "antiéticas" ou não. Apenas um respondente indicou explicitamente condição financeira para justificar sua ausência destas práticas. Pelo aspecto financeiro percebemos certos fenômenos recorrentes. Há crítica econômica ou capitalista embasando as ações, há uma razão de subversão dos valores econômicos de empresas vistas por eles como excessivamente ricas ou poderosas. Pensam nos menos privilegiados e poderosos, ao passo de que certos respondentes são categoricamente contra engajar em prática nociva ou negativa contra entidades que eles percebem como vulneráveis, desprivilegiadas ou bem-intencionadas, por exemplo, desenvolvedoras de jogos indie ou programadores individualizados. É perceptível o senso de responsabilidade ou dolo simbólico, respondentes indicam maturidade em suas ações e chegam ao ponto do compromisso em ressarcir as partes que eles consideram como prejudicadas em um futuro, "Acredito fortemente em recompensar conteúdo de qualidade" ou "[...] quando pude, comprei produtos originais que antes havia consumido de forma ilegal".

Sobre responsabilidade epistêmica, ou respondentes indicaram sentir culpa ou desagrado com suas práticas ou não se importam, ambos sendo uma minoria dissociada. Por exemplo, "Sei que não deveria ter feito isso, mas não queria reprovar por 6 décimos" ou "Sei que o que eu faço é contra a lei mas moralmente não vejo nenhum problema".

Há uma frente tímida pelo ideal de conhecimento livre, grupo pequeno de respondentes que acredita que o saber deve ser franqueado, aberto e acessível, "A discussão de ética na Computação não deve valer só para o indivíduo, não é ético que pesquisas financiadas por investimento público tenham seus resultados bloqueados por paywall, então não acredito que o uso do sci-hub seja antiético embora se encaixe nos critérios descritos".

Uma minoria, menos de 5\% dos respondentes, é contrário ou condena estas práticas. Outros são relativistas, condenam umas e não outras, e outros praticam, mesmo assim condenam. Por exemplo, "Concordo que nenhum destes itens devem ser cometidos, respeitando a propriedade intelectual de cada empresa/ indivíduo" ou "[...] a série é antiga então acredito que não esteja mais na Netflix. Interessei-me por ela depois de assistir a alguns episódios na Twitch.tv durante uma live. Mas não sou a favor da pirataria, e baixar essa série não me deixa $100 \%$ confortável [...]”.

Uma minoria apresentou reações empáticas, onde eles se colocam na posição daqueles que percebem como lesados pelas práticas. Por exemplo, "Não me sentia culpado por ter origem pobre e piratear conteúdos a anos, porém após me tornar desenvolvedor me sinto mal por piratear software/jogos, e evito ao máximo". Outra minoria expressou uma ideia de "imoralidade inescapável", de que estas práticas são inevitáveis na realidade tal qual vivemos, "Algumas dessa práticas são quase inevitáveis". 
Alguns testemunhos desligaram a prática do respondente ao que compreendemos como má-fé, isto é, ausente a intenção de dolo ou prejuízo. Por exemplo, “"colei' na EAD, mas os professores não condenam a prática e sabem que ela ocorre (alguns encorajam)", e mesmo assim o respondente indicou isso como uma prática "antiética", apesar do contexto determiná-la como moralmente aceita e permissível.

O resultado preocupante apontou uma maioria de respondentes com perspetivas éticas relativistas. Observamos que determinados respondentes possuem valores morais relativos sem crítica contundente do contexto ou cenário ao seu redor, apesar de evitarmos juízo de valor moral pontual, é digno de nota que este viés, seja por alienação ou ignorância ingênua, é prejudicial à construção de uma perspectiva ética coletivizada e consciente. Isto é, os mesmos estão desmunidos de episteme bem-fundamentada sobre a realidade que os permita travar um embate ideológico sobre as circunstâncias tecnopolíticas que os cercam. Por exemplo, "Porém, em alguns casos, na minha cabeça, não fará diferença para o autor das obras por exemplo", esta declaração de que o juízo da uma estruturação da realidade individualizada ("na minha cabeça") demonstra determinadas lacunas na instrução tecnopolítica em Computação. Nós pesquisadores não recebemos nada pela nossa produção intelectual, científica e acadêmica formal, enquanto empresas dedicadas ao mercado editorial exploram este mercado construído através da nossa produção.

\section{Discussão e conclusão}

Neste trabalho coletamos dados e informações através de um questionário e apresentamos uma análise sobre as práticas de, em maioria, especialistas em Computação no ciberespaço, relacionadas à Computação em si. Dialogamos a partir da Ética da Resistência como princípio ético, tratando primariamente de elementos concretos e materiais da realidade, como condição financeira, ou simbólicos, como privilégio e poder.

Propomos um recorte de EDM para Computação Aplicada com foco em Sistemas de Informação, ISEDM. Exploramos as respostas do questionário com foco neste recorte, estudando cenários "antiéticos" ou "imorais" declarados pelos respondentes, envolvendo tópicos adicionais à técnica. A complexidade da tomada de decisão mediante dilemas éticos é proporcional ao cenário envolvido, conforme mais dimensões e variáveis são associadas, menos nítida ou objetiva é a precisão da decisão. Como observamos nesta pesquisa, a realidade é complexa, multifacetada e plural, de constante disputa entre entidades, como é alinhada à Ética da Resistência.

Analisamos as respostas de quatro questões específicas sobre práticas percebidas pelos respondentes como "antiéticas" ou "imorais" nos últimos dois meses, codificamos e categorizamos as respostas. Disto, extraímos os seguintes achados, a motivação principal é financeira e a maioria das ações envolve PI, como "pirataria", o tipo de arquivo de maior ocorrência são livros (23\%), demonstrando que há interesse em conhecimento e cultura, e filmes $(21 \%)$, entretenimento. A maioria dos respondentes $(\approx 57 \%)$ aponta apenas uma prática. Infrações acadêmicas se resumem à "cola" em avaliações. Acompanhadas destas, percebemos outras diversas categorias associadas às práticas, como responsabilidade epistêmica sobre suas ações, manifestações ideológicas em favor do saber livre ou críticas econômicas às empresas e ao sistema capitalista. Cabe reforçar que esta pesquisa foge de objetos de lei, moralismo categórico ou utilitarismo idealista, ao invés de julgar, condenar e rotular negativamente, a intenção é construir vias alternativas inclusivas e 
emancipadoras, pelo ideal da Ética da Resistência em si. Se o futuro nos pertence e somos responsáveis por ele, vamos pensar em um para todos nós?

Pelos princípios do alicerce ético, é imperativo que a análise ultrapasse a contribuição semântica e proponha encaminhamentos práticos. Ações que amenizem ou resolvam os problemas percebidos, aliados às manifestações dos respondentes para um ciberespaço menos "antiético": (i) oferecer versões parciais de produtos e serviços, para degustação e análise de qualidade; (ii) revisão de preços e transparência sobre os mesmos; (iii) recuperação e disponibilização de conteúdo à esfera digital, como filmes e séries antigas, facilitando sua descoberta; (iv) melhor integração entre plataformas de streaming, com preços acessíveis, para que usuários tenham conteúdo em ecossistema compartilhado; (v) docentes disponibilizem diretamente os próprios materiais que solicitem em suas disciplinas; (vi) em suas disciplinas, docentes solicitem materiais acessíveis e abertos; (vii) docentes realizem avaliações construtivas e formativas, evitando a pressão da avaliação tradicional; (viii) pesquisas e desenvolvimento financiados com dinheiro público devem ser disponibilizados publicamente, com retorno à sociedade; (ix) alternativas para remunerar os pesquisadores e cientistas pelas suas produções intelectuais publicadas; (x) apoiar produtores de conteúdo em financiamento coletivo e fortalecer empresas de desenvolvimento de menor porte, com maior transparência.

Como encaminhamentos de pesquisa futuros, abordar outros públicos-alvo, acompanhar cada um dos tópicos percebidos neste pesquisa em detalhes, avançar o tema de Ética da Resistência em Computação, com engajamento de demais interessados.

\section{Referências}

Alakavuklar, O. e Alamgir, F. (2018). Ethics of resistance in organisations: A conceptual proposal. J. Bus. Ethics, 149:31-43.

Bar-Yam, Y. (2002). General features of complex systems. EOLSS - UNESCO Encyclopedia of Life Support Systems.

Barcaro, E. e Freire, E. (2009). A importância da disciplina Ética no curso de informática. Fasci-Tech, 01(01):17-28.

Barger, R. (2008). Computer Ethics: A Case-Based Approach. Cambridge University Press, Cambridge, RU.

Bender, E. M., Gebru, T., McMillan-Major, A., e Shmitchell, S. (2021). On the dangers of stochastic parrots: Can language models be too big? In Proceedings of the 2021 ACM FAccT, FAccT '21, pp. 610-623. ACM.

Bohr, R. H. e Kaplan, H. M. (1971). Employee protest and social change in the health care organization. Am. j. of pub. health, 61(11):2229-2235.

Carvalho, L. P., Oliveira, J., e Santoro, F. (2020). Who watches you? an allegory of dataveillance and cyberstalking. In Anais do I WICS, pp. 85-96, Porto Alegre, RS, Brasil. SBC.

Christians, C. G. (2007). Neutral science and the ethics of resistance. In Denzin, N. K. e Giardina, M. D., (eds), Ethical Futures in Qualitative Research. Routledge. Routledge.

Eriksen, K. (2021). WHY DISNEY+ IS RIGHT TO CHARGE EXTRA FOR 'RAYA'. https://cutt.ly/oxTe49X. Acessado: 20/03/2021. 
Ferraz, C. A. (2014). Ética Elementos Básicos. NEPFIL online, Pelotas, RS.

Fieser, J. (2020). Ethics. In The Internet encyclopedia of philosophy. https://iep.utm.edu/ethics/. Acessado: 20/03/2021.

Gregor, S. (2006). The nature of theory in information systems. MISQ, 30(3):611-642.

Habermas, J. (1997). Direito e Democracia, entre facticidade e validade, volume 2. Tempo Brasileiro, Rio de Janeiro, RJ.

Klikauer, T. (2014). Social justice and the ethics of resistance: A review essay. Soc Just Res, 27:518-525.

Lima, K. (2021). Animação "Raya e o Último Dragão" chegará ao Disney+ no mesmo dia que aos cinemas por valor adicional. https://cutt.ly/jxTwZtx. Acessado: 20/03/2021.

Lisboa, L., Ferro, J. V., Brito, J. R., e Lopes, R. (2020). A disseminação da desinformação promovida por líderes estatais na pandemia da COVID-19. In Anais do I WICS, pp. 114-121, Porto Alegre, RS, Brasil. SBC.

Luca Casali, G. e Perano, M. (2020). Forty years of research on factors influencing ethical decision making: Establishing a future research agenda. Journal of Bus. Res.

Masiero, P. C. (2013). Ética em Computação. EDUSP, São Paulo, SP.

Oliveira, F. (2020). Por melhores condições, entregadores protestam em SP, RJ e outros estados. https://cutt.ly/WxTrLQm. Acessado: 20/03/2021.

Recker, J. (2013). Scientific research in information systems: a beginner's guide. Springer-Verlag Berlin Heidelberg.

Ribeiro, K. S. F. M., Maciel, C., e S. Bim, M. A. (2020). Gênero e tecnologias. In Maciel, C. e Viterbo, J., (eds), Computação e sociedade: a profissão - volume 1, pp. 104-140. EdUFMT Digital, Mato Grosso, Brasil.

Schaefer, S. (2020). Why Mulan Is So Expensive On Disney+. https://cutt.ly/RxTw5Ee. Acessado: 20/03/2021.

Silva, T. (2020). Comunidades, algoritmos e ativismos digitais: Olhares afrodiaspóricos. LiteraRUA, São Paulo, SP.

Silveira, S. A. (2020). Responsabilidade algorítmica, personalidade eletrônica e democracia. Eptic, 22(2).

Sklair, L. (2012). Culture-Ideology of Consumerism. Blackwell Publishing Ltd.

Sovacool, B. (2014). Energy studies need social science. Nature, 511(7511):529-530.

Sposito, C. (2011). O ensino da ética em cursos de computação : normativo ou dialógico? Master's thesis, UFMT, Instituto de Educação, Mato Grosso, MT.

Stair, R. M. e Reynolds, G. W. (2018). Principles of Information Systems. CENGAGE Learning, Boston, MA, $13^{\mathrm{a}}$ edição.

Strauss, A. L. (1987). Qualitative Analysis for Social Scientists. Cambridge University.

Torres, M. (1998). Ethical decision-making models. https://media.iese.edu/research/pdfs/DI-0358-E.pdf. Acessado: 20/03/2021. 